\title{
Neural Correlates of Self-referential Processing and Their Clinical Implications in Social Anxiety Disorder
}

\author{
Hyung-Jun Yoon ${ }^{1}$, Eun Hyun Seo ${ }^{2}$, Jae-Jin Kim³ , IL Han Choo ${ }^{1}$ \\ ${ }^{1}$ Department of Neuropsychiatry, Chosun University Hospital, College of Medicine, Chosun University, ${ }^{2}$ Premedical Science, College of \\ Medicine, Chosun University, Gwangju, ${ }^{3}$ Department of Psychiatry and Institute of Behavioral Science in Medicine, Yonsei University College \\ of Medicine, Seoul, Korea
}

\begin{abstract}
Social anxiety disorder (SAD) is associated with aberrant self-referential processing (SRP) such as increased self-focused attention. Aberrant SRP is one of the core features of SAD and is also related to therapeutic interventions. Understanding of the underlying neural correlates of SRP in SAD is important for identifying specific brain regions as treatment targets. We reviewed functional magnetic resonance imaging ( $\mathrm{FMRI}$ ) studies to clarify the neural correlates of SRP and their clinical implications for SAD. Task-based and resting $\mathrm{FMRI}$ studies have reported the cortical midline structures including the default mode network, theory of mind-related regions of the temporo-parietal junction and temporal pole, and the insula as significant neural correlates of aberrant SRP in SAD patients. Also, these neural correlates are related to clinical improvement on pharmacological and cognitive-behavioral treatments. Furthermore, these could be candidates for the development of novel SAD treatments. This review supports that neural correlates of SAD may be significant biomarkers for future pathophysiology based treatment.
\end{abstract}

KEY WORDS: Social anxiety disorder; Self-referential processing; Functional magnetic resonance imaging; Cortical midline structures.

\section{INTRODUCTION}

Social anxiety disorder (SAD), one of the common psychiatric disorders with a lifetime prevalence rate of $12.1 \%,{ }^{1)}$ is thought to develop at an early age and progress to other psychiatric disorders, such as depressive disorder and drug abuse. ${ }^{2)}$ SAD is characterized by marked fear with respect to social situations, which expose the individuals to possible scrutiny by others. ${ }^{3)}$ As a response to the fearful social stimuli, emotional hyper-reactivity and dysregulation of emotion have been observed in SAD. ${ }^{4,5)}$ Besides the emotional hyper-reactivity to fearful stimuli, SAD patients show hypersensitivity to self-related feedback. ${ }^{6}$

Received: January 3, 2018 / Revised: March 14, 2018

Accepted: April 27, 2018

Address for correspondence: IL Han Choo, MD, PhD Department of Neuropsychiatry, Chosun University Hospital, College of Medicine, Chosun University, 365 Pilmun-daero,

Dong-gu, Gwangju 61453, Korea

Tel: +82-62-220-3104, Fax: +82-62-225-3659

E-mail: ilhan.choo@chosun.ac.kr

ORCID: https://orcid.org/0000-0001-6547-9735
Self-referential processing (SRP) is the process of relating information to the self ${ }^{77}$; this is aberrantly heightened in SAD during social situations. ${ }^{8)}$ SAD patients frequently focus their attention on detailed monitoring and observation of themselves in social situations. ${ }^{9)}$ This feature of awareness of the self as a social object is known as "public self-consciousness", which is heightened in SAD. ${ }^{10,11)}$ Consequently, they show excessive self-focused attention during social situations. ${ }^{12,13)}$ They are also sensitive to evaluation by others and tend to ruminate about themselves or view themselves from the perspective of the observer. ${ }^{14)}$ Exaggerated SRP has been suggested not only as one of the important components of the explanatory models of SAD, ${ }^{12,13)}$ but also as the focus of therapeutic intervention such as cognitive-behavioral therapy $(\mathrm{CBT}) .{ }^{15)}$ This self-focused cognitive process has been linked to dysfunction in the brain regions involved in SRP and the theory of mind (ToM). ${ }^{16,17)}$ In functional neuroimaging, SRP has been associated with the cortical midline structures (CMS) as well as the ToM-related regions. ${ }^{7)}$ CMS such as the medial prefrontal cortex

(c) This is an Open-Access article distributed under the terms of the Creative Commons Attribution Non-Commercial License (http://creativecommons.org/licenses/by-nc/4.0) which permits unrestricted non-commercial use, distribution, and reproduction in any medium, provided the original work is properly cited. 
(MPFC) and posterior cingulate cortex (PCC)/precuneus are known to play a critical role in $\mathrm{SRP}_{,}^{7,18)}$ and share common features with intrinsic activity of the default mode network (DMN). ${ }^{19)}$ ToM or mentalizing, the ability to read the minds of others, is mediated by a brain network including the MPFC, temporo-parietal junction (TPJ), posterior end of superior temporal sulcus (pSTS), and temporal pole (TP). ${ }^{20,21)}$ According to simulation theory, it is proposed that an observer attributes mental states to another person by using one's own mind as a model of the other mind, suggesting that self-related information may play an anchor point for understanding others $^{22,23)}$ Thus, ToM may depend on SRP such as self-reflection.

Previous functional magnetic resonance imaging (fMRI) studies on SAD have mainly investigated emotional reactivity to various facial expressions, and have found significant hyperactivation in the limbic/paralimbic regions including the amygdala, ${ }^{24-26)}$ anterior cingulate cortex (ACC), ${ }^{27)}$ and insula. ${ }^{25,28)}$ Especially, the predominant finding implicating the amygdala indicates that this region and its connections play a crucial role in SAD. ${ }^{4)}$ Beyond the amygdala, hyperactivation of the brain regions related with SRP and ToM has been observed during SRP in SAD. ${ }^{6}$ Previous $\mathrm{fMRI}$ studies on SAD have found that the activation of SRP- and ToM-related regions was normalized by CBT and cognitive reappraisal ${ }^{29,30)}$ as well as pharmacotherapy, ${ }^{31,32)}$ implying that changes in SRP may be important in the treatment of SAD.

Resting state fMRI research on the functional connectivity in brain network has attracted greater attention as a tool to elucidate the neurobiological basis of psychiatric disorders, including Alzheimer's disease, major depressive disorder (MDD), and schizophrenia. ${ }^{33)}$ Resting state functional connectivity (RSFC) measures the temporal correlation of spontaneous blood oxygen level-dependent (BOLD) signals between spatially distant brain regions without an explicit task. ${ }^{33,34)}$ Traditional activation paradigms cannot assess network connectivity and its abnormality related to the alterations of intrinsic neural activity of BOLD signals observed in resting state $\mathrm{AMRI} .{ }^{35}$ ) Meanwhile, RSFC provides a broader network representation of the functional architecture of the brain. ${ }^{34)}$ Given that proper connection and harmonious interaction between brain regions are critical for optimal brain functioning, investigations of RSFC may offer a better under- standing of the underlying neurobiology of SAD. ${ }^{36)}$ Further, considering that SRP is believed to predominate at resting state, ${ }^{37)}$ differences of RSFC between SAD patients and controls could reflect intrinsic functional abnormalities related to SRP in SAD. Recently, pattern classification of RSFC has been applied to discriminate patients with SAD from controls. ${ }^{38,39)}$

Based on the advances in our understanding of the neurocircuitry of $S A D$, growing literature has begun to emphasize important alterations of SRP and its neural correlates in SAD. ${ }^{40)}$ Here, we present a review of functional neuroimaging studies on investigation of the neural correlates of aberrant SRP in SAD. First, we reviewed the current findings drawn from task-based fMRI studies that addressed the role of CMS and other brain regions during SRP in SAD. These studies were discussed together with related literature to facilitate the elucidation of the underlying role of CMS and other regions in aberrant SRP of $\mathrm{SAD}$. Along with this, we reviewed the neural correlates of SRP that have been implicated in SAD. Furthermore, given the function of DMN involvement in SRP, ${ }^{19,41,42)}$ we summarized the results of RSFC data that suggest abnormalities of DMN function in SAD, which could result in aberrant SRP. Finally, we considered current evidence suggesting that the neural activities associated with aberrant SRP may be normalized by various therapeutic interventions. Through a literature review, we elaborated on the underlying neural correlates of aberrant SRP in $\mathrm{SAD}$ and discussed their clinical implications.

\section{MAIN FINDINGS}

\section{Neural Correlates of SRP}

SRP is defined as the process by which a person becomes aware that specific contents of the stimuli are strongly related to one's own self." To date, the neural correlates of SRP have been extensively investigated using self-referential stimuli of various domains such as verbal, memory, and emotion. Previous task-based fMRI studies on SRP used a rather broad definition of self-related tasks describing all tasks where some content had to be related to the persons themselves. ${ }^{7)}$ Meta-analysis of fMRI studies on self has revealed that SRP is mediated by CMS including the MPFC, medial orbitofrontal cortex (OFC), ACC, and PCC/precuneus. ${ }^{718)}$ These anatomical brain regions may be considered as a functional unit for several 
reasons. First, co-activation among the separate CMS has been observed in various paradigms. ${ }^{18)}$ Second, strong functional connectivity among the CMS has also been reported during self-referential tasks. ${ }^{43)}$ Third, the CMS show high resting state activity/interconnectivity and task-induced deactivation. This distinctive functional characteristic overlaps with the DMN activity reflecting intrinsic brain functions. ${ }^{42,44)}$ The DMN, a set of temporally correlated brain regions, is more active during resting state and deactivated during attention-demanding tasks. ${ }^{42,44)}$ This network includes the MPFC, PCC/precuneus, TPJ, and angular gyrus. As an intrinsically organized network, the DMN engages in stimulus-independent, self-generated thought during resting conditions, ${ }^{19,41,42)}$ and plays a pivotal role in self-conscious and self-related mental representations. ${ }^{45)}$

The CMS are presumed to mediate introspective processing such as reflection, evaluation, and recollection of oneself $^{46-48)}$ as well as emotional and reward processing. ${ }^{49,50)}$ According to neuroscience literature, the function of the MPFC has been divided between the dorsal and ventral regions, with the dorsal MPFC being more associated with mentalizing ${ }^{51-53)}$ and the ventral MPFC more responsible for affective aspects of SRP ${ }^{54)}$ Further, the dorsal MPFC has also been known to be engaged in introspective processing including evaluation and reflection of oneself ${ }^{46,47,55)}$ and SRP that involves personal semantic facts. ${ }^{56)}$ Along with the insula, the ACC forms the salience network, and plays a key role in attentional control. ${ }^{57,58)}$ The ACC appears to be important for directing attention towards self during self-reflection, ${ }^{54)}$ and can be a possible mediator of post-event rumination. ${ }^{59)}$ As a central hub of the DMN, the PCC is thought to be involved in evaluating whether a certain stimulus is self-related by consulting the autobiographical memory. ${ }^{19,54)}$ Besides the CMS, other brain regions including the insula, TPJ, and TP are assumed to be involved in SRP. ${ }^{19,54,60)}$ The insula has been associated with interoceptive sensation, the monitoring of the internal emotion-related physiological state ${ }^{61-64)}$ and bodily self-consciousness. ${ }^{65)}$ The TPJ and TP have been mainly suggested as the neural correlates of $\mathrm{ToM}^{20)}$ but both the brain regions are also involved in self-referential information processing, such as bodily self-consciousness and coherent self-perception ${ }^{19,54,66)}$ and perspective taking. ${ }^{67)}$ The inferior parietal lobule (IPL), which is considered a part of the mirror neu- ron system has been implicated in bodily self-perception including self-face recognition ${ }^{68,69)}$ and attention process such as salience detection. ${ }^{70)}$

\section{Aberrant SRP in SAD}

Generally, self-focused attention is regarded as an awareness of self-referential and internally generated information, which is composed of information regarding bodily states, thoughts, attitude, memories, emotions, and moods. ${ }^{71)}$ When confronted with a social situation, SAD patients tend to shift their attention to a process of detailed, self-focused observation, and this enhances the awareness of self-relevant thoughts, emotions, and internal sensation. ${ }^{12)}$ Excessive self-focused attention is important in generating as well as maintaining pathological social anxiety. ${ }^{12,13)}$ The cognitive model of social anxiety proposes that aberrantly increased self-focused attention during social situations is a core feature of SAD because it enhances access to negative thoughts and feelings concerning the self, and prevents the patient with SAD from observing objective external information that may disconfirm negative fears and expectations. ${ }^{12)}$ Accordingly, exaggerated self-focused attention seems to have a negative impact on the self-concepts and intensifies social anxiety ${ }^{72,73)}$ Furthermore, it may induce a bias towards an unpleasant awareness of the observable self ${ }^{12,14)}$ as well as poor social performance and social withdrawal. ${ }^{73-75)}$ Finally, excessive self-focused attention was found to decrease along with improvements of social anxiety following successful $\mathrm{CBT}^{8,73)}$ suggesting that the attentional strategies that reduce self-focused attention should be considered in the treatment of SAD. This characteristic of increased self-focused attention may be connected to abnormal activation of the brain regions related to SRP. In line with the hypothesis of increased self-focused attention, abnormal activation of the CMS has been observed repeatedly during exposure to self-referential or disorder-related stimuli in SAD. ${ }^{16,17,31,76-79)}$

One of core concerns of SAD patients is the fear of being negatively evaluated by others. ${ }^{80)}$ Owing to attention to the observable self, SAD patients show heightened public self-consciousness than those of other anxiety disorders such as panic disorder or as observed in controls during social situations, ${ }^{11,81)}$ and the degree of public self-consciousness has been found to correlate positively with the severity of social anxiety. ${ }^{10,82}$ Furthermore, 
heightened public self-consciousness in SAD patients allows them to see themselves from the perspective of the other person as an actor in social situations, and this "observer perspective" is in contrast to a "field perspective" in which the individuals view a situation from their own perspective. ${ }^{83)}$ SAD patients rather than the controls were more likely to adopt an observer perspective, ${ }^{83}$ which as compared to a field perspective was associated with more negative thoughts and increased anxiety. ${ }^{84}$ Further, SAD patients ultimately fear the notion of the observable self as a target of disapproval from others, ${ }^{80)}$ and engage in a detailed review or post-event rumination on their performance following a social situation. ${ }^{12,13)}$ Considering the excessive preoccupation with the evaluation by others in SAD, these patients may excessively monitor not only their performance or mental representations but also the mental state of others, indicating the dysfunction of brain regions involved in ToM. Several fMRI studies on SAD examining the mentalizing or SRP reported abnormal activation of the ToM-related regions. ${ }^{78,85,86)}$

\section{Self-referential Task Implicating Involvement of CMS, Insula and ToM-related Regions in SAD}

First, an $\mathrm{fMRI}$ study to directly investigate SRP using the self- versus other-referential criticism and praise revealed selectively increased BOLD signals in response to self-referential criticism within both, the MPFC and amygdala, in SAD patients as compared with those in controls. ${ }^{16)}$ Also, functional connectivity between the MPFC and amygdala was significantly increased for SAD patients than controls in response to self-referential criticism. ${ }^{16)}$ These findings suggest that abnormal hyperactivation of the MPFC may result from hypersensitivity to salient self-referential stimuli as well as post-event rumination. An fMRI study applying tasks related to negative self-beliefs found increased activation of the CMS (MPFC and PCC/precuneus), angular gyrus, IPL, amygdala, and parahippocampal gyrus while reacting to negative self-belief versus asterisk counting in SAD. ${ }^{77)}$ In one study, ${ }^{78)}$ positive and negative social trait adjectives were presented to SAD patients during an SRP task. SAD patients showed hyperactivity in the CMS (MPFC, subgenual ACC, and PCC/precuneus) and language processing regions (ventrolateral PFC) as well as visual processing regions (fusiform and lingual gyrus) during SRP. SRP occurs following social transgressions, and unintentional transgressions could lead to embarrassment particularly in SAD. ${ }^{76)}$ In the fMRI study investigating social norm processing, SAD patients as compared with the controls showed markedly increased activation to unintentional than the intentional transgressions, within the ventral MPFC. ${ }^{76)}$ Given the hypervigilance to self-evaluation during embarrassing events in $\mathrm{SAD}$, abnormal hyperactivation of the ventral MPFC may reflect an increased propensity of self-focused attention.

For a detailed examination of self-referentiality, specifically whether increased BOLD signals of the MPFC result from an exaggerated representation of their own opinions or those of others, an fMRI study, ${ }^{17)}$ which used the comments of the first or second person viewpoint, identified significant groups (SAD and controls) based on viewpoint interactions in the ventral MPFC. SAD patients exhibited increased BOLD signals to second relative to first person viewpoint, whereas the controls showed increased signals to the first relative to second viewpoint. In addition, decreased BOLD signals of the ventral MPFC to first person viewpoint in SAD significantly correlated with the severity of symptoms. Meanwhile, SAD patients compared with controls showed increased activations in the dorsal MPFC to self-referential comments irrespective of viewpoints. Therefore, these distinct activation patterns of the MPFC may reflect not only an increased tendency to adopt the observer perspective, but also enhanced self-focused attention or evaluation on self-referential comments. In line with SAD, hyperactivation of the MPFC was found during self-focused attention in subjects with high social anxiety than subjects with low social anxiety, and the degree of MPFC activation was positively correlated with the level of self-focused attention. ${ }^{87)}$

Instead of self-referential verbal stimuli, social stimuli capable of possibly inducing SRP have been used in previous fMRI studies on SAD. Being looked at in front of others may provoke self-focused attention and/or observer perspective as well as feelings of scrutiny in SAD. A study found abnormal activation to eye contact in the posterior CMS and other regions related to SRP in SAD. ${ }^{311}$ Compared with controls, SAD patients showed increased activation in the PCC and IPL during direct eye contact compared with away from eye contact, reflecting heightened SRP such as increased self-focused attention and experience of observer perspective. A study focusing on the DMN revealed a lower deactivation of PCC/precuneus in 
SAD patients than controls during a face perception task, suggesting that impairment of the DMN may be related with self-focused attention in SAD. ${ }^{88)}$ On the contrary, a significantly decreased activation of the PCC/precuneus while performing a social situation task was reported in SAD patients than in controls. ${ }^{89)}$ Another study with high and low socially anxious individuals found a significant positive correlation between the PCC activation for the contrast, self-focused versus outward attention, and the trait of self-focused attention in high socially anxious individuals. $^{87)}$

Recently, two fMRI studies using disorder-related visual scenes have reported the hyperactivation of the CMS (dorsal MPFC and PCC/precuneus) and insula as well as amygdala in response to disorder-related versus neutral scenes in SAD. ${ }^{90,91)}$ In one fMRI study ${ }^{92)}$ investigating the attentional bias toward internal and external social threats, participants were exposed to internal threat (pulse-sounds) and external threat (facial crowds) while performing a visual search task. SAD patients showed increased activation in the PCC and middle temporal gyrus in response to the external threat and positive correlation between the PCC activation and severity of social anxiety. Additionally, significant interaction effects of internal and external focuses were observed in the PCC and visual occipital cortex in SAD patients. Interaction effect within the PCC may result from increased self-focused attention while looking at the self through the observer perspective in front of others. While focusing on the internal threat, a prominently increased activation of the rostral ACC, insula, and OFC was demonstrated in SAD patients, and insula activation during the internal focus was positively correlated with the level of social anxiety. A study exploring the neural correlates of anticipatory anxiety has shown an increased activation of the insula during anticipation of public speech evaluated by others in SAD patients than in controls. ${ }^{93)}$ In aspects of self-relatedness, the insula mediates not only the processing of emotional self-referential stimuli, ${ }^{7,94)}$ but also social anxiety-related interoceptive sensibility. ${ }^{95)}$

A recent $f M R I$ study found increased activation in the ToM-related regions as well as the CMS and insula during self-referential working memory tasks in SAD. ${ }^{86)}$ In this study, subjects underwent $\mathrm{fMRI}$ scanning while performing a working memory task consisting of faces with self-referential positive or negative evaluative comments.
Compared with controls, SAD patients showed increased activation in the CMS (dorsal MPFC and PCC), insula, and TPJ during encoding, and TPJ activation was positively correlated with the level of the fear for negative evaluation. The prominent hyperactivation of the CMS and TPJ during encoding may result from not only increased self-focused attention, but also excessive mentalization or increased tendency of adopting the observer perspective. In another fMRI study ${ }^{96)}$ using a self-focused emotion regulation task, SAD patients as compared with the controls demonstrated hyperactivation in the PCC and ToM-related regions such as the TPJ and pSTS during the viewing of aversive compared with neutral pictures, suggesting increased bodily self-consciousness and heightened adoption of the perspective of others. Boehme et al. ${ }^{87)}$ asked high and low socially anxious subjects to focus their attention either inwardly or outwardly when watching a simulated social situation. Compared to low socially anxious subjects, high socially anxious subjects showed increased activation in the MPFC, TPJ, and TP during self-focused attention. Furthermore, SRP was accompanied by increased activation in the MPFC, PCC, and TP in individuals with subclinical social anxiety. ${ }^{97)}$ Collectively, these findings suggest that abnormal hyperactivation of the ToM-related brain regions as well as the CMS may be associated with atypical processing of self-referential information in SAD.

To summarize, although the number of $\mathrm{fMRI}$ studies focusing on SRP in SAD is limited, evidence from these studies consistently suggests hyperactivation of the CMS, ToM-related regions and insula during SRP (Table 1 and Fig. 1). Overall hyperactivity of these regions may reflect aberrant SRP such as increased self-focused attention and heightened public self-consciousness, which underlines the psychopathology of SAD.

\section{Resting State Functional Abnormalities of DMN in SAD}

Resting single photon emission computed tomography study on SAD reported alteration of regional cerebral blood flow (rCBF) in critical regions of the DMN. ${ }^{98)}$ In this study, SAD patients as compared with the controls showed increased perfusion in the frontal cortex and decreased perfusion in the precuneus. In a fluorodeoxyglucose-positron emission tomography (PET) study, ${ }^{99)}$ decreased glucose metabolism at rest was found in the 
Table 1. Task-based fMRI studies investigating self-referential processing in SAD

\begin{tabular}{|c|c|c|c|}
\hline Study & Sample & Type of task and stimuli & Main findings \\
\hline $\begin{array}{l}\text { Blair et al. } \\
(2008)^{16)}\end{array}$ & $\begin{array}{l}17 \mathrm{SAD} \\
17 \mathrm{HC}\end{array}$ & $\begin{array}{l}\text { Self- versus other-referential comments (positive, } \\
\text { negative, and neutral) }\end{array}$ & $\begin{array}{l}\uparrow \mathrm{MPFC} \text { and amygdala activation to self-referential } \\
\text { negative comments in SAD than in HC }\end{array}$ \\
\hline $\begin{array}{l}\text { Goldin et al. } \\
(2009)^{78)}\end{array}$ & $16 \mathrm{SAD}$ & $\begin{array}{l}\text { Self-referential processing task: positive and negative } \\
\text { social trait adjectives }\end{array}$ & $\begin{array}{l}\uparrow \mathrm{MPFC} \text {, subgenual ACC, PCC/precuneus and } \\
\text { ventrolateral PFC activation to positive or negative } \\
\text { self-referential processing in SAD }\end{array}$ \\
\hline $\begin{array}{l}\text { Goldin et al. } \\
(2010)^{77)}\end{array}$ & $16 \mathrm{SAD}$ & $\begin{array}{l}\text { Negative self-beliefs task: self-focused, negative } \\
\text { self-beliefs }\end{array}$ & $\begin{array}{l}\uparrow \text { MPFC, PCC/precuneus, angular gyrus, IPL, amygdala, } \\
\text { and parahippocampal gyrus activation to reacting } \\
\text { negative self-belief in SAD }\end{array}$ \\
\hline $\begin{array}{l}\text { Blair et al. } \\
(2010)^{76)}\end{array}$ & $\begin{array}{l}16 \mathrm{SAD} \\
16 \mathrm{HC}\end{array}$ & $\begin{array}{l}\text { Social norm processing task: intentional and } \\
\text { unintentional social transgressions }\end{array}$ & $\begin{array}{l}\uparrow \text { Ventral MPFC to unintentional relative to intentional } \\
\text { transgressions in SAD than in HC }\end{array}$ \\
\hline $\begin{array}{l}\text { Blair et al. } \\
(2011)^{17)}\end{array}$ & $\begin{array}{l}15 \mathrm{SAD} \\
15 \mathrm{HC}\end{array}$ & $\begin{array}{l}\text { Self-referential comments of } 1 \text { st or } 2 \text { nd person viewpoint } \\
\text { (positive, negative, and neutral) }\end{array}$ & $\begin{array}{l}\uparrow \text { Ventral MPFC to } 2 \text { nd relative } 1 \text { st viewpoint in SAD than } \\
\text { in HC. Reduced BOLD signals in ventral MPFC to } 1 \text { st } \\
\text { viewpoint correlated with severity of social anxiety in } \\
\text { SAD }\end{array}$ \\
\hline $\begin{array}{l}\text { Schneier et al. } \\
(2011)^{31)}\end{array}$ & $\begin{array}{l}16 \mathrm{SAD} \\
16 \mathrm{HC}\end{array}$ & $\begin{array}{l}\text { Faces simulating } 3 \text { directions of eye gaze: direct, averted, } \\
\text { and neutral }\end{array}$ & $\begin{array}{l}\uparrow \mathrm{PCC} \text { and IPL activation during direct eye contact } \\
\text { compared to away from eye contact in SAD than in HC }\end{array}$ \\
\hline $\begin{array}{l}\text { Boehme et al. } \\
(2013)^{93)}\end{array}$ & $\begin{array}{l}17 \mathrm{SAD} \\
17 \mathrm{HC}\end{array}$ & $\begin{array}{l}\text { Anticipation of public and evaluated speaking versus } \\
\text { control condition }\end{array}$ & $\begin{array}{l}\uparrow \text { Insula activation during anticipation of public speech } \\
\text { evaluated by others compared to control condition in } \\
\text { SAD than in HC }\end{array}$ \\
\hline $\begin{array}{r}\text { Choi et al. } \\
(2016)^{92)}\end{array}$ & $\begin{array}{l}20 \mathrm{SAD} \\
20 \mathrm{HC}\end{array}$ & $\begin{array}{l}\text { Visual search task: internal threat (own pulse-sound) and } \\
\text { external threat (facial crowds) }\end{array}$ & $\begin{array}{l}\uparrow \mathrm{PCC} \text { and middle temporal gyrus activation to external } \\
\text { threat in SAD } \\
\uparrow \text { Rostral ACC, insula, and OFC activation to internal } \\
\text { threat in SAD }\end{array}$ \\
\hline $\begin{array}{l}\text { Yoon et al. } \\
(2016)^{86)}\end{array}$ & $\begin{array}{l}20 \mathrm{SAD} \\
20 \mathrm{HC}\end{array}$ & $\begin{array}{l}\text { Self-referential working memory task: face making a } \\
\text { positive or negative comment }\end{array}$ & $\begin{array}{l}\uparrow \text { Dorsal MPFC, PCC, TPJ, and insula activation during } \\
\text { encoding in SAD than in HC }\end{array}$ \\
\hline
\end{tabular}

fMRI, functional magnetic resonance imaging; SAD, social anxiety disorder; $\mathrm{HC}$, healthy controls; $\uparrow$, increased; MPFC, medial prefrontal cortex; ACC, anterior cingulate cortex; PCC, posterior cingulate cortex; PFC, prefrontal cortex; IPL, inferior parietal lobule; BOLD, blood oxygen level-dependent; OFC, orbitofrontal cortex; TPJ, temporo-parietal junction.

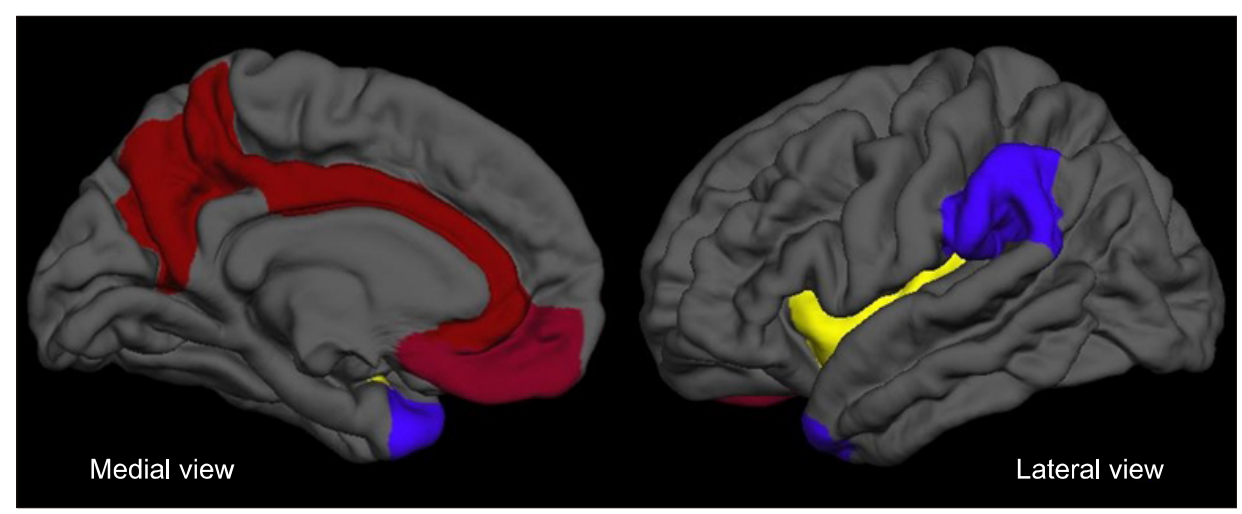

Fig. 1. Medial and lateral view of significant neural correlates of aberrant self-referential processing and treatment response consistently observed in task-based and resting state functional magnetic resonance imaging studies on social anxiety disorder. Red areas represent the cortical midline structures including the default mode network (medial prefrontal cortex, anterior cingulate cortex, and posterior cingulate cortex/precuneus). Purple areas represent the theory of mind-related regions (temporo-parietal junction and temporal pole). Yellow areas represent the insula.

MPFC and ACC in SAD patients compared with the controls, implying resting state metabolic abnormalities in the DMN. Previous resting state fMRI studies have reported abnormalities of DMN functional connectivity in SAD. An fMRI study ${ }^{100)}$ applying a regional homogeneity (ReHo) method reflecting temporal synchrony of regional BOLD signals found decreased coherence within the DMN including the MPFC and angular gyrus in SAD patients than in the controls, suggesting functional impairment of self-related mental representation in the absence of social 
stimuli. The fMRI study using the graph theory method found decreased RSFC strength in the bilateral precuneus in SAD patients compared with controls. ${ }^{101)}$ Additionally, the RSFC strength in the precuneus exhibited a significant negative correlation with illness duration, suggesting the underlying role of the precuneus in the neural pathophysiology of SAD. In fact, the precuneus is a critical hub of the DMN, and plays a key role in SRP. ${ }^{45)}$ The study of Liao et al. ${ }^{102)}$ applying independent component analysis (ICA) found alterations of RSFC in self-referential network (SRN) including the DMN in SAD. SAD patients as compared with the controls exhibited increased RSFC in the ventral MPFC of the SRN and the dorsal MPFC of the DMN, which is consistent with the cognitive model of social anxiety addressing increased tendency towards self-awareness and monitoring in an upcoming social situation. ${ }^{13)}$ Furthermore, RSFC strength of the dorsal MPFC positively correlated with symptom severity. In contrast, decreased RSFC in the PCC/precuneus of the DMN was found in SAD patients than in the controls, which is in line with a previous finding of lower deactivation in the PCC/precuneus during specific tasks. ${ }^{88)}$ These RSFC abnormalities of the DMN support the cognitive-behavioral model of SAD, which theorize that the mode of self-focused processing is activated not only during a social situation, but also prior to and following the social situation. ${ }^{12)}$ In an fMRI study by Geiger et al., ${ }^{103)}$ decreased RSFC in the PCC was also observed in SAD patients than in the controls. In a recent fMRI study, ${ }^{104)}$ RSFC was predicted by the diagnostic status within a single unified analysis of covariance (ANCOVA) model. The authors of this study found significantly increased RSFC within the DMN (between the MPFC and PCC) in SAD patients than in the controls. This result may reflect excessive introspection and rumination during rest in SAD. However, in other fMRI studies on SAD, no significant differences of the RSFC within the DMN were found between SAD patients and controls. ${ }^{92,105)}$

The fMRI study by Liu et al..$^{38)}$ using multivariate pattern analysis (MVPA) explored the potential of RSFC to discriminate SAD patients from controls, and reported a correct classification rate of $82.5 \%$. In this study, the authors found that the consensus functional connections employed in the discrimination of SAD were largely located within or across the DMN, sensory-motor network, visual network, and cerebellar regions. Notably, the medial
OFC and precuneus of the DMN among these regions most prominently showed a higher weight than other regions in the classification for SAD. Another study of a relatively large sample exploring the diagnostic potential of ReHo underlying the neural correlates of SAD, using MVPA, reported that the diagnostic accuracy of ReHo was $76.25 \% .{ }^{39)}$ The MPFC, among the regions showing different discriminating values between $\mathrm{SAD}$ and control groups, was found with the highest weight in SAD diagnosis. Beyond the DMN, a recent fMRI study ${ }^{106)}$ applying functional connectivity density (FCD) analysis in conjunction with RSFC and discriminant analysis identified altered RSFC in self- and ToM-related networks in SAD. SAD patients as compared with the controls exhibited decreased long-range FCD in the rostral ACC and decreased short-range FCD in the superior temporal gyrus (STG), which is involved in the ToM. ${ }^{107)}$ Furthermore, discriminant analysis showed that altered RSFC within the STG and between the rostral ACC and superior/middle frontal gyrus contributed most prominently to SAD diagnosis, with an accuracy of $84.5 \%$.

In summary, in spite of the heterogeneity of the analytical methods and occasional negative findings, ${ }^{92,105)}$ most studies consistently have reported abnormalities of RSFC within the DMN in SAD. These DMN functional abnormalities may indicate that the aberrant SRP of SAD such as anticipatory or post-event rumination takes place during resting conditions as well as social situations. In addition, emerging evidence suggests that the altered RSFC of the DMN in SAD seems to be especially prominent within the CMS. Thus, the altered resting state functional connections within the CMS may be to influence the hyperactivity of CMS during self-referential tasks. Further, emerging findings from MVPA based on RSFC data provide evidence for the possibility of RSFC as a potential diagnostic tool for SAD. Table 2 summarizes the findings of resting state fMRI studies investigating the DMN functional connectivity in SAD.

\section{SRP-related Regions as Target of Treatment in SAD}

The SRP-related brain regions including the CMS and insula have been found to be important for pharmacologic treatment response in SAD. In an oxygen-15 PET study, ${ }^{108)}$ SAD patients showed decreased rCBF in response to public speaking, in the PCC as well as amygdala along with significant symptom reduction after treatment 
Table 2. Resting state fMRI studies investigating DMN functional connectivity in SAD

\begin{tabular}{|c|c|c|c|}
\hline Study & Sample & Examined regions/network and analytic method & Main findings \\
\hline $\begin{array}{l}\text { Liao et al. } \\
\quad(2010)^{102)}\end{array}$ & $\begin{array}{l}17 \mathrm{SAD} \\
19 \mathrm{HC}\end{array}$ & $\begin{array}{r}\text { Identified } 8 \text { res } \\
\text { component a }\end{array}$ & $\begin{array}{l}\uparrow \text { RSFC in ventral MPFC of SRN in SAD than in HC } \\
\uparrow \text { RSFC in dorsal MPFC of DMN in SAD than in HC } \\
\downarrow \text { RSFC in the PCC/precuneus of DMN in SAD than in HC }\end{array}$ \\
\hline $\begin{array}{l}\text { Qiu et al. } \\
(2011)^{100)}\end{array}$ & $\begin{array}{l}20 \mathrm{SAD} \\
20 \mathrm{HC}\end{array}$ & Whole brain analysis: regional homogeneity method & $\begin{array}{l}\downarrow \text { Coherence in MPFC and angular gyrus within DMN in } \\
\text { SAD than in HC }\end{array}$ \\
\hline $\begin{array}{l}\text { Liu et al. } \\
\quad(2015)^{1011}\end{array}$ & $\begin{array}{l}20 \mathrm{SAD} \\
20 \mathrm{HC}\end{array}$ & Whole brain analysis: graph theory & $\begin{array}{l}\downarrow \text { RSFC in the bilateral precuneus in SAD than in HC. } \\
\text { Negative correlation between RSFC strength in the } \\
\text { precuneus and the illness duration in SAD }\end{array}$ \\
\hline $\begin{array}{l}\text { Liu et al. } \\
(2015)^{38)}\end{array}$ & $\begin{array}{l}16 \mathrm{SAD} \\
16 \mathrm{HC}\end{array}$ & $\begin{array}{l}\text { Whole brain analysis: multivariate pattern analysis } \\
\text { method }\end{array}$ & $\begin{array}{l}\text { Medial OFC and precuneus of DMN were the regions with } \\
\text { the highest weight in diagnosis of SAD }\end{array}$ \\
\hline $\begin{array}{l}\text { Zhang et al. } \\
(2015)^{39)}\end{array}$ & $\begin{array}{l}40 \mathrm{SAD} \\
40 \mathrm{HC}\end{array}$ & $\begin{array}{l}\text { Whole brain analysis: regional homogeneity and } \\
\text { multivariate pattern analysis method }\end{array}$ & $\begin{array}{l}\text { MPFC was the region with the highest weight in diagnosis } \\
\text { of SAD }\end{array}$ \\
\hline $\begin{array}{l}\text { Rabany et al. } \\
(2017)^{104)}\end{array}$ & $\begin{array}{l}8 \mathrm{SAD} \\
19 \mathrm{HC}\end{array}$ & $\begin{array}{l}\text { Identified } 3 \text { resting state network: a single unified } \\
\text { ANCOVA method }\end{array}$ & $\uparrow$ RSFC within DMN (MPFC-PCC) in SAD than in HC \\
\hline
\end{tabular}

fMRI, functional magnetic resonance imaging; DMN, default mode network; SAD, social anxiety disorder; HC, healthy controls; $\uparrow$, increased; $\downarrow$, decreased; RSFC, resting state functional connectivity; MPFC, medial prefrontal cortex; SRN, self-referential network; OFC, orbitofrontal cortex; ANCOVA, analysis of covariance; PCC, posterior cingulate cortex.

with the selective serotonin reuptake inhibitor (SSRI), citalopram. Warwick et al. ${ }^{109)}$ reported that the resting rCBF within the bilateral insula decreased with improvement of social anxiety following pharmacotherapy with both, citalopram and moclobemide in SAD. In this study, a significant correlation was found between symptom reduction and decreased $\mathrm{rCBF}$ in the bilateral insula and PCC. Schneier et al. ${ }^{31)}$ examined neural responses to the SSRI, paroxetine, in SAD patients, for 8 weeks. Compared to the baseline, the PCC/precuneus and insula activation significantly decreased, and symptom improvement was associated with a decrease in BOLD signals in the CMS (MPFC, ACC, and PCC/precuneus) and IPL after treatment. Giménez et al..$^{32)}$ found decreased neural response in the MPFC and ACC compared to the baseline, after 8 weeks of paroxetine treatment, in SAD patients along with clinical improvement. In contrast, the increased activation of these regions was sustained in the placebo group, which showed persistence of elevated clinical anxiety until the end of the study. In addition, the analysis of RSFC using ICA showed that paroxetine decreased the RSFC in the insula and ACC. Particularly, both, alterations of the BOLD signals and RSFC in the rostral MPFC, produced by paroxetine significantly correlated with clinical improvement, suggesting that the medial prefrontal regions may be the main areas associated with the therapeutic effect of standard SSRI treatments.

Besides pharmacotherapy, several psychological interventions involving $\mathrm{CBT}$ and emotion regulation techni- ques reported normalization of the abnormal activation of SRP- and ToM-related regions in SAD. A study by Klumpp et al. ${ }^{29)}$ found that hyperactivation of the CMS (DMPFC and medial $\mathrm{OFC}$ ) and insula at baseline significantly decreased after successful CBT in SAD patients. Interestingly, greater pretreatment neural response in the medial OFC was associated with greater symptom improvement following CBT. In another fMRI study ${ }^{96)}$ on SAD, increased activation of the dorsal PCC and bilateral temporo-parietal regions during exposure to aversive stimuli was normalized by emotion regulation through self-focused appraisal. Similarly, applying the emotion regulation by cognitive control led to significant reduction of activity within the insula, precuneus, and bilateral temporo-parietal regions as well as the amygdala in $\mathrm{SAD}{ }^{30)}$

It is known that SAD can be treated effectively with both pharmacological and psychological treatments. ${ }^{110)}$ Nevertheless, a substantial number of SAD patients do not respond to adequate pharmacotherapy with SSRI or CBT, ${ }^{111,112)}$ which underlines the need for development of new treatments. Magnetic resonance-guided focused ultrasound surgery (MRgFUS) has gained attention as a minimally invasive thermal lesioning technique for the treatment of Parkinson's disease and obsessive-compulsive disorder. ${ }^{113,114)}$ Recently, Kim et al. ${ }^{115)}$ reported the case of a patient with treatment-resistant MDD who showed remarkable symptom improvement following bilateral anterior capsulotomy via MRgFUS. There is growing evidence 
that abnormally increased activity of the anterior CMS plays a major role in the development and treatment of MDD. ${ }^{116)}$ Considering the hyperactivity of CMS associated with aberrant SRP in SAD, the CMS may be the potential target regions for new treatment of SAD applying MRgFUS.

\section{CONCLUSION}

This review summarized the current findings of functional neuroimaging studies that investigated the neural correlates of aberrant SRP in SAD. Despite the clinical importance of SRP, until now, there have been few fMRI studies to explore the underlying neural mechanism of SRP directly in SAD. Although there are concerns regarding insufficient amount of literature and some discrepancies between studies, there appears to be a common convergence on the idea of the CMS playing a crucial role in aberrant SRP in SAD. Evidence derived from task-based as well as resting state fMRI data supports this hypothesis. Abnormal hyperactivation of the CMS during SRP has been reported consistently in SAD. In addition, although there are some inconsistent findings, abnormalities of the RSFC within the DMN have been observed repeatedly and its alterations seem to be most prominent in the CMS. Therefore, aberrant SRP in SAD appears to be associated with the predominant hyperactivation of CMS that may be affected by altered functional connections at the resting state. In accordance with this, the updated neurobiological model of SAD highlights the hyperactivation of CMS and insula as well as the amygdala. ${ }^{177)}$ Furthermore, this model proposes that functional decoupling of the posteromedial hub of DMN (PCC/precuneus) from other brain networks (limbic and ventral attention network) could lead to deficits in bottom-up activation regulation, implying the underlying role of the posterior CMS in SAD. In addition, current evidence suggests that the ToM-related region and insula as well as the CMS may be important in abnormal SRP and treatment response in SAD (Fig. 1). From a clinical perspective, a significant change of activities in the SRP-related regions following successful treatments and association of these changes and symptom improvement imply that more specific therapeutic approaches, targeting aberrant SRP and its neural correlates, may be candidates for novel effective treatment for SAD. Moreover, emerging findings suggesting a mean- ingful diagnostic potential of RSFC data in distinguishing SAD from healthy conditions provides the basis for potential use of RSFC as a complementary method in clinical diagnosis of SAD. Future research to investigate more close associations between various neurobiological alterations and change of SRP could broaden our understanding regarding the distinctive role of SRP in SAD, and contribute to the development of novel therapeutic interventions for SAD.

\section{- Acknowledgments}

This study was supported by grants from the Clinical Research Medicine Institute at Chosun University Hospital (2016).

\section{REFERENCES}

1. Kessler RC, Berglund P, Demler O, Jin R, Merikangas KR, Walters EE. Lifetime prevalence and age-of-onset distributions of DSM-IV disorders in the National Comorbidity Survey Replication. Arch Gen Psychiatry 2005;62:593-602.

2. Sadock BJ, Sadock VA, Ruiz P. Kaplan \& Sadock's synopsis of psychiatry: behavioral sciences/clinical psychiatry. 11th ed. Philadelphia, London:Wolters Kluwer/Lippincott Williams \& Wilkins;2015. $1472 p$.

3. American Psychiatric Association; DSM-5 Task Force. Diagnostic and statistical manual of mental disorders, 5th ed. (DSM-5.) Washington, D.C.: American Psychiatric Association; 2013. $947 p$.

4. Freitas-Ferrari MC, Hallak JE, Trzesniak C, Filho AS, Machado-de-Sousa JP, Chagas MH, et al. Neuroimaging in social anxiety disorder: a systematic review of the literature. Prog Neuropsychopharmacol Biol Psychiatry 2010;34: 565-580.

5. Etkin A, Wager TD. Functional neuroimaging of anxiety: a meta-analysis of emotional processing in PTSD, social anxiety disorder, and specific phobia. Am J Psychiatry 2007;164: 1476-1488.

6. Blair KS, Blair RJR. A cognitive neuroscience approach to generalized anxiety disorder and social phobia. Emot Rev 2012;4:133-138.

7. Northoff G, Heinzel A, de Greck M, Bermpohl F, Dobrowolny $\mathrm{H}$, Panksepp J. Self-referential processing in our brain--a meta-analysis of imaging studies on the self. Neuroimage 2006;31:440-457.

8. Spurr JM, Stopa L. Self-focused attention in social phobia and social anxiety. Clin Psychol Rev 2002;22:947-975.

9. Clark DM. A cognitive perspective on social phobia. In: Crozier WR, Alden LE, editors. International handbook of social anxiety: concepts, research, and interventions relating to the self and shyness. Chichester, New York:John Wiley \& Sons;2001. p.405-430. 
10. Fenigstein A, Scheier MF, Buss AH. Public and private self-consciousness: assessment and theory. J Consult Clin Psychol 1975;43:522-527.

11. Bruch MA, Heimberg RG. Differences in perceptions of parental and personal characteristics between generalized and nongeneralized social phobics. J Anxiety Disord 1994;8: 155-168.

12. Clark DM, Wells A. A cognitive model of social phobia. In: Heimberg RG, Liebowitz MR, Hope DA, Schneier FR, editors. Social phobia: diagnosis, assessment, and treatment. New York:Guilford Press;1995. p.69-93.

13. Rapee RM, Heimberg RG. A cognitive-behavioral model of anxiety in social phobia. Behav Res Ther 1997;35:741-756.

14. Hackmann A, Surawy C, Clark DM. Seeing yourself through others' eyes: a study of spontaneously occurring images in social phobia. Behav Cogn Psychother 1998;26:3-12.

15. Hofmann SG, Moscovitch DA, Kim HJ, Taylor AN. Changes in self-perception during treatment of social phobia. I Consult Clin Psychol 2004;72:588-596.

16. Blair K, Geraci M, Devido J, McCaffrey D, Chen G, Vythilingam $M$, et al. Neural response to self-and other referential praise and criticism in generalized social phobia. Arch Gen Psychiatry 2008;65:1176-1184.

17. Blair KS, Geraci M, Otero M, Majestic C, Odenheimer S, Jacobs $\mathrm{M}$, et al. Atypical modulation of medial prefrontal cortex to self-referential comments in generalized social phobia. Psychiatry Res 2011;193:38-45.

18. Northoff G, Bermpohl F. Cortical midline structures and the self. Trends Cogn Sci 2004;8:102-107.

19. Qin P, Northoff G. How is our self related to midline regions and the default-mode network? Neuroimage 2011;57: 1221-1233.

20. Frith $\mathrm{CD}$, Frith $U$. The neural basis of mentalizing. Neuron 2006; 50:531-534.

21. Saxe R, Kanwisher N. People thinking about thinking people. The role of the temporo-parietal junction in "theory of mind". Neuroimage 2003;19:1835-1842.

22. Gallese V, Goldman A. Mirror neurons and the simulation theory of mind-reading. Trends Cogn Sci 1998;2:493-501.

23. Epley N, Keysar B, Van Boven L, Gilovich T. Perspective taking as egocentric anchoring and adjustment. I Pers Soc Psychol 2004;87:327-339.

24. Stein MB, Goldin PR, Sareen J, Zorrilla LT, Brown GG. Increased amygdala activation to angry and contemptuous faces in generalized social phobia. Arch Gen Psychiatry 2002; 59:1027-1034.

25. Straube T, Mentzel HJ, Miltner WH. Common and distinct brain activation to threat and safety signals in social phobia. Neuropsychobiology 2005;52:163-168.

26. Phan KL, Fitzgerald DA, Nathan PJ, Tancer ME. Association between amygdala hyperactivity to harsh faces and severity of social anxiety in generalized social phobia. Biol Psychiatry 2006;:59:424-429.
27. Amir N, Klumpp H, Elias J, Bedwell JS, Yanasak N, Miller LS. Increased activation of the anterior cingulate cortex during processing of disgust faces in individuals with social phobia. Biol Psychiatry 2005;57:975-981.

28. Straube T, Kolassa IT, Glauer M, Mentzel HJ, Miltner WH. Effect of task conditions on brain responses to threatening faces in social phobics: an event-related functional magnetic resonance imaging study. Biol Psychiatry 2004;56:921-930.

29. Klumpp H, Fitzgerald DA, Phan KL. Neural predictors and mechanisms of cognitive behavioral therapy on threat processing in social anxiety disorder. Prog Neuropsychopharmacol Biol Psychiatry 2013;45:83-91.

30. Brühl $A B$, Herwig $U$, Delsignore $A$, Jäncke $L$, Rufer $M$. General emotion processing in social anxiety disorder: neural issues of cognitive control. Psychiatry Res 2013;212: 108-115.

31. Schneier FR, Pomplun M, Sy M, Hirsch J. Neural response to eye contact and paroxetine treatment in generalized social anxiety disorder. Psychiatry Res 2011;194:271-278.

32. Giménez $M$, Ortiz $H$, Soriano-Mas $C$, López-Solà $M$, Farré $\mathrm{M}$, Deus J, et al. Functional effects of chronic paroxetine versus placebo on the fear, stress and anxiety brain circuit in social anxiety disorder: initial validation of an imaging protocol for drug discovery. Eur Neuropsychopharmacol 2014;24: 105-116.

33. Lee $M H$, Smyser CD, Shimony JS. Resting-state fMRI: a review of methods and clinical applications. AJNR Am J Neuroradiol 2013;34:1866-1872.

34. Woodward ND, Cascio CJ. Resting-state functional connectivity in psychiatric disorders. JAMA Psychiatry 2015;72: 743-744.

35. Fox MD, Snyder AZ, Vincent JL, Corbetta M, Van Essen DC, Raichle ME. The human brain is intrinsically organized into dynamic, anticorrelated functional networks. Proc Natl Acad Sci U S A 2005; 102:9673-9678.

36. Etkin A, Prater KE, Schatzberg AF, Menon V, Greicius MD. Disrupted amygdalar subregion functional connectivity and evidence of a compensatory network in generalized anxiety disorder. Arch Gen Psychiatry 2009;66:1361-1372.

37. Gusnard DA, Akbudak E, Shulman GL, Raichle ME. Medial prefrontal cortex and self-referential mental activity: relation to a default mode of brain function. Proc Natl Acad Sci U S A 2001;98:4259-4264.

38. Liu F, Guo W, Fouche JP, Wang Y, Wang W, Ding J, et al. Multivariate classification of social anxiety disorder using whole brain functional connectivity. Brain Struct Funct 2015;220:101-115.

39. Zhang W, Yang X, Lui S, Meng Y, Yao L, Xiao Y, et al. Diagnostic prediction for social anxiety disorder via multivariate pattern analysis of the regional homogeneity. Biomed Res Int 2015;2015:763965.

40. Stein DJ. Social anxiety disorder and the psychobiology of self-consciousness. Front Hum Neurosci 2015;9:489. 
41. Mason MF, Norton MI, Van Horn JD, Wegner DM, Grafton ST, Macrae CN. Wandering minds: the default network and stimulus-independent thought. Science 2007;315:393-395.

42. Andrews-Hanna JR, Smallwood J, Spreng RN. The default network and self-generated thought: component processes, dynamic control, and clinical relevance. Ann N Y Acad SCi 2014; 1316:29-52.

43. Greicius MD, Krasnow B, Reiss AL, Menon V. Functional connectivity in the resting brain: a network analysis of the default mode hypothesis. Proc Natl Acad Sci U S A 2003; 100:253-258.

44. Raichle ME, Snyder AZ. A default mode of brain function: a brief history of an evolving idea. Neuroimage 2007;37: 1083-1090; discussion 1097-1099.

45. Cavanna AE, Trimble MR. The precuneus: a review of its functional anatomy and behavioural correlates. Brain 2006; 129:564-583.

46. Johnson SC, Baxter LC, Wilder LS, Pipe JG, Heiserman JE, Prigatano GP. Neural correlates of self-reflection. Brain 2002;125:1808-1814.

47. Zysset S, Huber O, Ferstl E, von Cramon DY. The anterior frontomedian cortex and evaluative judgment: an $\mathrm{fMRI}$ study. Neuroimage 2002; 15:983-991.

48. Fossati P, Hevenor SJ, Lepage M, Graham SJ, Grady C, Keightley ML, et al. Distributed self in episodic memory: neural correlates of successful retrieval of self-encoded positive and negative personality traits. Neuroimage 2004;22: 1596-1604.

49. Fossati P, Hevenor SJ, Graham SJ, Grady C, Keightley ML, Craik F, et al. In search of the emotional self: an FMRI study using positive and negative emotional words. Am J Psychiatry 2003;160:1938-1945.

50. Hwang S, Meffert H, VanTieghem MR, White SF, Sinclair S, Bookheimer SY, et al. Neurodevelopmental changes in social reinforcement processing: a functional magnetic resonance imaging study. Clin Psychopharmacol Neurosci 2017:15:369-381.

51. Mitchell JP, Macrae CN, Banaji MR. Dissociable medial prefrontal contributions to judgments of similar and dissimilar others. Neuron 2006;50:655-663.

52. Mitchell JP, Banaji MR, Macrae CN. The link between social cognition and self-referential thought in the medial prefrontal cortex. J Cogn Neurosci 2005; 17:1306-1315.

53. Gallagher $\mathrm{HL}$, Happé F, Brunswick N, Fletcher PC, Frith $\mathrm{U}$, Frith CD. Reading the mind in cartoons and stories: an fMRI study of 'theory of mind' in verbal and nonverbal tasks. Neuropsychologia 2000;38:11-21.

54. van der Meer L, Costafreda S, Aleman A, David AS. Self-reflection and the brain: a theoretical review and meta-analysis of neuroimaging studies with implications for schizophrenia. Neurosci Biobehav Rev 2010;34:935-946.

55. Kelley WM, Macrae CN, Wyland CL, Caglar S, Inati S, Heatherton TF. Finding the self? An event-related fMRI study.
J Cogn Neurosci 2002; 14:785-794.

56. Moran JM, Heatherton TF, Kelley WM. Modulation of cortical midline structures by implicit and explicit self-relevance evaluation. Soc Neurosci 2009;4:197-211.

57. Seeley WW, Menon V, Schatzberg AF, Keller J, Glover GH, Kenna $\mathrm{H}$, et al. Dissociable intrinsic connectivity networks for salience processing and executive control. I Neurosci 2007;27:2349-2356.

58. Menon V, Uddin LQ. Saliency, switching, attention and control: a network model of insula function. Brain Struct Funct 2010;214:655-667.

59. Xie K, Kuang H, Tsien JZ. Mild blast events alter anxiety, memory, and neural activity patterns in the anterior cingulate cortex. PLoS One 2013;8:e64907.

60. Olson IR, Plotzker A, Ezzyat Y. The enigmatic temporal pole: a review of findings on social and emotional processing. Brain 2007;130:1718-1731.

61. Damasio AR, Grabowski TJ, Bechara A, Damasio H, Ponto LL, Parvizi J, et al. Subcortical and cortical brain activity during the feeling of self-generated emotions. Nat Neurosci 2000;3:1049-1056.

62. Paulus MP, Stein MB. An insular view of anxiety. Biol Psychiatry 2006;60:383-387.

63. Critchley HD, Wiens S, Rotshtein P, Ohman A, Dolan RJ. Neural systems supporting interoceptive awareness. Nat Neurosci 2004;7:189-195.

64. Craig AD. How do you feel--now? The anterior insula and human awareness. Nat Rev Neurosci 2009;10:59-70.

65. Ronchi R, Bello-Ruiz J, Lukowska M, Herbelin B, Cabrilo I, Schaller K, et al. Right insular damage decreases heartbeat awareness and alters cardio-visual effects on bodily self-consciousness. Neuropsychologia 2015;70:11-20.

66. Blanke O, Arzy S. The out-of-body experience: disturbed self-processing at the temporo-parietal junction. Neuroscientist 2005;11:16-24.

67. Agarwal SM, Shivakumar V, Kalmady SV, Danivas V, Amaresha AC, Bose A, et al. Neural correlates of a perspective-taking task using in a realistic three-dimmensional environment based task: a pilot functional magnetic resonance imaging study. Clin Psychopharmacol Neurosci 2017;15:276-281.

68. Platek SM, Loughead JW, Gur RC, Busch S, Ruparel K, Phend $\mathrm{N}$, et al. Neural substrates for functionally discriminating self -face from personally familiar faces. Hum Brain Mapp 2006;27:91-98.

69. Kim MK, Yoon HJ, Shin YB, Lee SK, Kim JJ. Neural basis of distorted self-face recognition in social anxiety disorder. Neuroimage Clin 2016;12:956-964.

70. Singh-Curry V, Husain M. The functional role of the inferior parietal lobe in the dorsal and ventral stream dichotomy. Neuropsychologia 2009;47:1434-1448.

71. Ingram RE. Self-focused attention in clinical disorders: review and a conceptual model. Psychol Bull 1990;107:156- 
176.

72. Bögels SM, Lamers CT. The causal role of self-awareness in blushing-anxious, socially-anxious and social phobics individuals. Behav Res Ther 2002;40:1367-1384.

73. Bögels SM, Mansell W. Attention processes in the maintenance and treatment of social phobia: hypervigilance, avoidance and self-focused attention. Clin Psychol Rev 2004;24:827-856.

74. Alden LE, Teschuk M, Tee K. Public self-awareness and withdrawal from social interactions. Cognit Ther Res 1992;16: 249-267.

75. McManus F, Sacadura C, Clark DM. Why social anxiety persists: an experimental investigation of the role of safety behaviours as a maintaining factor. J Behav Ther Exp Psychiatry 2008;39:147-161.

76. Blair KS, Geraci M, Hollon N, Otero M, DeVido J, Majestic $\mathrm{C}$, et al. Social norm processing in adult social phobia: atypically increased ventromedial frontal cortex responsiveness to unintentional (embarrassing) transgressions. Am J Psychiatry 2010;167:1526-1532.

77. Goldin PR, Gross JJ. Effects of mindfulness-based stress reduction (MBSR) on emotion regulation in social anxiety disorder. Emotion 2010;10:83-91.

78. Goldin P, Ramel W, Gross J. Mindfulness meditation training and self-referential processing in social anxiety disorder: behavioral and neural effects. J Cogn Psychother 2009;23: 242-257.

79. Brühl AB, Rufer M, Delsignore A, Kaffenberger T, Jäncke L, Herwig U. Neural correlates of altered general emotion processing in social anxiety disorder. Brain Res 2011;1378: 72-83.

80. Roth DA, Heimberg RG. Cognitive-behavioral models of social anxiety disorder. Psychiatr Clin North Am 2001;24: 753-771.

81. Saboonchi F, Lundh LG, Ost LG. Perfectionism and self-consciousness in social phobia and panic disorder with agoraphobia. Behav Res Ther 1999;37:799-808.

82. Hope DA, Heimberg RG. Public and private self-consciousness and social phobia. J Pers Assess 1988;526:626-639.

83. Wells A, Clark DM, Ahmad S. How do I look with my minds eye: perspective taking in social phobic imagery. Behav Res Ther 1998:36:631-634.

84. Spurr JM, Stopa L. The observer perspective: effects on social anxiety and performance. Behav Res Ther 2003;41:10091028.

85. Sripada CS, Angstadt M, Banks S, Nathan PJ, Liberzon I, Phan $\mathrm{KL}$. Functional neuroimaging of mentalizing during the trust game in social anxiety disorder. Neuroreport 2009;20: 984-989.

86. Yoon HJ, Kim JS, Shin YB, Choi SH, Lee SK, Kim JJ. Neural activity during self-referential working memory and the underlying role of the amygdala in social anxiety disorder. Neurosci Lett 2016;627:139-147.
87. Boehme S, Miltner WH, Straube T. Neural correlates of self-focused attention in social anxiety. Soc Cogn Affect Neurosci 2014;10:856-862.

88. Gentili C, Ricciardi E, Gobbini MI, Santarelli MF, Haxby JV, Pietrini P, et al. Beyond amygdala: default mode network activity differs between patients with social phobia and healthy controls. Brain Res Bull 2009;79:409-413.

89. Nakao T, Sanematsu H, Yoshiura T, Togao O, Murayama K, Tomita M, et al. $\mathrm{fMRI}$ of patients with social anxiety disorder during a social situation task. Neurosci Res 2011;69:67-72.

90. Heitmann CY, Feldker K, Neumeister P, Zepp BM, Peterburs J, Zwitserlood P, et al. Abnormal brain activation and connectivity to standardized disorder-related visual scenes in social anxiety disorder. Hum Brain Mapp 2016;37:15591572.

91. Heitmann $C Y$, Feldker K, Neumeister P, Brinkmann L, Schrammen E, Zwitserlood $\mathrm{P}$, et al. Brain activation to task-irrelevant disorder-related threat in social anxiety disorder: the impact of symptom severity. Neuroimage Clin 2017; 14:323-333.

92. Choi SH, Shin JE, Ku J, Kim JJ. Looking at the self in front of others: neural correlates of attentional bias in social anxiety. J Psychiatr Res 2016;75:31-40.

93. Boehme S, Ritter V, Tefikow S, Stangier U, Strauss B, Miltner $\mathrm{WH}$, et al. Brain activation during anticipatory anxiety in social anxiety disorder. Soc Cogn Affect Neurosci 2014;9: 1413-1418.

94. Northoff G, Schneider F, Rotte M, Matthiae C, Tempelmann C, Wiebking C, et al. Differential parametric modulation of self-relatedness and emotions in different brain regions. Hum Brain Mapp 2009;30:369-382.

95. Terasawa Y, Shibata M, Moriguchi Y, Umeda S. Anterior insular cortex mediates bodily sensibility and social anxiety. Soc Cogn Affect Neurosci 2013;8:259-266.

96. Gaebler M, Daniels JK, Lamke JP, Fydrich T, Walter H. Behavioural and neural correlates of self-focused emotion regulation in social anxiety disorder. J Psychiatry Neurosci 2014,39:249-258.

97. Abraham A, Kaufmann C, Redlich R, Hermann A, Stark R, Stevens $S$, et al. Self-referential and anxiety-relevant information processing in subclinical social anxiety: an fMRI study. Brain Imaging Behav 2013;7:35-48.

98. Warwick JM, Carey P, Jordaan GP, Dupont P, Stein DJ. Resting brain perfusion in social anxiety disorder: a voxel-wise whole brain comparison with healthy control subjects. Prog Neuropsychopharmacol Biol Psychiatry 2008; 32:1251-1256.

99. Evans KC, Simon NM, Dougherty DD, Hoge EA, Worthington JJ, Chow C, et al. A PET study of tiagabine treatment implicates ventral medial prefrontal cortex in generalized social anxiety disorder. Neuropsychopharmacology 2009;34:390-398.

100. Qiu C, Liao W, Ding J, Feng Y, Zhu C, Nie X, et al. Regional 
homogeneity changes in social anxiety disorder: a resting-state fMRI study. Psychiatry Res 2011;194:47-53.

101. Liu F, Zhu C, Wang Y, Guo W, Li M, Wang W, et al. Disrupted cortical hubs in functional brain networks in social anxiety disorder. Clin Neurophysiol 2015;126:17111716.

102. Liao W, Chen H, Feng Y, Mantini D, Gentili C, Pan Z, et al. Selective aberrant functional connectivity of resting state networks in social anxiety disorder. Neuroimage 2010;52: 1549-1558.

103. Geiger MJ, Domschke K, Ipser J, Hattingh C, Baldwin DS, Lochner C, et al. Altered executive control network resting-state connectivity in social anxiety disorder. World J Biol Psychiatry 2016;17:47-57.

104. Rabany L, Diefenbach GJ, Bragdon LB, Pittman BP, Zertuche $\mathrm{L}$, Tolin DF, et al. Resting-state functional connectivity in generalized anxiety disorder and social anxiety disorder: evidence for a dimensional approach. Brain Connect 2017;7:289-298.

105. Pannekoek JN, Veer IM, van Tol MJ, van der Werff SJ, Demenescu LR, Aleman A, et al. Resting-state functional connectivity abnormalities in limbic and salience networks in social anxiety disorder without comorbidity. Eur Neuropsychopharmacol 2013;23:186-195.

106. Cui Q, Vanman EJ, Long Z, Pang Y, Chen Y, Wang Y, et al. Social anxiety disorder exhibit impaired networks involved in self and theory of mind processing. Soc Cogn Affect Neurosci 2017;12:1284-1295.

107. Schurz M, Radua J, Aichhorn M, Richlan F, Perner J. Fractionating theory of mind: a meta-analysis of functional brain imaging studies. Neurosci Biobehav Rev 2014;42: 9-34.

108. Furmark T, Appel L, Michelgård A, Wahlstedt K, Ahs F, Zancan S, et al. Cerebral blood flow changes after treatment of social phobia with the neurokinin-1 antagonist GR205171, citalopram, or placebo. Biol Psychiatry 2005; 58:132-142.
109. Warwick JM, Carey P, Van der Linden G, Prinsloo C, Niehaus D, Seedat S, et al. A comparison of the effects of citalopram and moclobemide on resting brain perfusion in social anxiety disorder. Metab Brain Dis 2006;21:241-252.

110. Stein MB, Stein DJ. Social anxiety disorder. Lancet 2008; 371:1115-1125.

111. Nagata T, Suzuki F, Teo AR. Generalized social anxiety disorder: a still-neglected anxiety disorder 3 decades since Liebowitz's review. Psychiatry Clin Neurosci 2015;69: 724-740.

112. Eskildsen A, Hougaard E, Rosenberg NK. Pre-treatment patient variables as predictors of drop-out and treatment outcome in cognitive behavioural therapy for social phobia: a systematic review. Nord I Psychiatry 2010;64:94-105.

113. Dobrakowski PP, Machowska-Majchrzak AK, LabuzRoszak B, Majchrzak KG, Kluczewska E, Pierzchała KB. MR-guided focused ultrasound: a new generation treatment of Parkinson's disease, essential tremor and neuropathic pain. Interv Neuroradiol 2014;20:275-282.

114. Jung HH, Chang WS, Rachmilevitch I, Tlusty T, Zadicario E, Chang JW. Different magnetic resonance imaging patterns after transcranial magnetic resonance-guided focused ultrasound of the ventral intermediate nucleus of the thalamus and anterior limb of the internal capsule in patients with essential tremor or obsessive-compulsive disorder. J Neurosurg 2015; 122:162-168.

115. Kim M, Kim CH, Jung HH, Kim SJ, Chang JW. Treatment of major depressive disorder via magnetic resonance-guided focused ultrasound surgery. Biol Psychiatry 2018;83: e17-e18.

116. Nejad AB, Fossati $P$, Lemogne C. Self-referential processing, rumination, and cortical midline structures in major depression. Front Hum Neurosci 2013;7:666.

117. Brühl AB, Delsignore A, Komossa K, Weidt S. Neuroimaging in social anxiety disorder-a meta-analytic review resulting in a new neurofunctional model. Neurosci Biobehav Rev 2014; 47:260-280. 